\title{
THE APPLICATION OF SUB INDEX AGGREGATION METHOD TO ASSESS THE HEALTH OF A WATER BODY
}

\author{
Lisa Crowley \& Niranjali Jayasuriya \\ School of Civil and Chemical Engineering, \\ RMIT University: Melboume, Australia
}

\begin{abstract}
The environmental health of inland water bodies can be described using water quality parameters that describe the physical, chernical and biological status of the water. Each of these parameters reflect different characteristics of the water body and can be assessed by comparing with threshold values detailed in water quality guidelines such as the Fresh Water and Marine Water Quality Guidelines. Assessing the status of a water body using a suite of water quality parameters is cumbersome and fraught with difficulty, as for a given location some parameters may fall under threshold values whilst others exceed guideline values. To simplify and unify the interpretation based on individual water quality parameters, these can be combined into a single dimensionless number by considering each measured water quality concentration and its corresponding guideline valuc. This single number is called the "water quality index' (WQI) and is used to assess the overall status of the water body quantitatively and objectively.
\end{abstract}

Many methods have been derived over the years to determine the WQI for different applications. These methods are grouped into two categories; 'sub-index' and 'statistical'. As to-date, no guidelines have been specified on the selection of a methodology. However, it has been acknowledged that the method used to derive the WQI should retain valuable information from each parameter and retain its contribution to determining the overall health during the combining process.

This paper reviews methods available to determine WQIs for a range of applications. The paper will describe the application of the SIA method to a set of water quality data along the Yarra River in Victoria, Australia. The results were useful in identifying the trend in WQ variation. The Sub Indices Aggregation (SIA) method could be used by Authorities for rapid assessment of water bodies to identify their suitability for different purposes based on the quality of water. Application of the ricthod can also assist with locating critical areas that could urgently require rehabilitation.

Proceedings of the Eighth Annual Forestry and Environment Symposium 2002 of the Department of Forestry and Environmental Science, Lniversity of Sri Jayewardenepura, Sri Lanka 